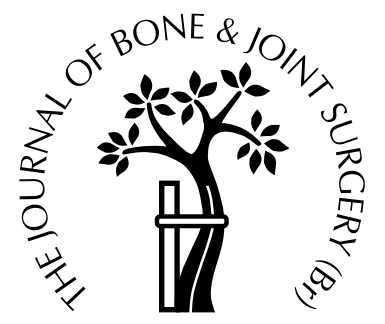

\title{
Revision of the Kotz type of tumour endoprosthesis for the lower limb
}

\author{
F. Mittermayer, R. Windhager, M. Dominkus, P. Krepler, \\ E. Schwameis, M. Sluga, R. Kotz, G. Strasser \\ From the University of Vienna, Austria
}

$I^{n}$ 251 patients over a period of 15 years an uncemented Kotz modular femoral and tibial reconstruction mega prosthesis was implanted after resection of a malignant tumour of the lower limb. Twenty-one patients $(8.4 \%)$ underwent revision for aseptic loosening, again using an uncemented prosthesis, and five of these required a further revision procedure. The median follow-up time from the first revision was 60 months (11 to 168) and after a second revision, 33 months ( 2 to 50 ). The probability of a patient avoiding aseptic loosening for ten years was $96 \%$ for a proximal femoral, $76 \%$ for a distal femoral and $85 \%$ for a proximal tibial implant.

At the time of follow-up all radiographs were assessed according to the International Symposium of Limb Salvage criteria. The first radiological signs of aseptic loosening were always seen at the most proximal or distal part of the anchorage stem at a mean of 12 months (4 to 23) after the first implantation. Using the Musculoskeletal Tumor Society score for evaluation, the clinical results showed a mean of $88 \%$ of normal function.

J Bone Joint Surg [Br] 2002;84-B:401-6. Received 27 February 2001; Accepted after revision 14 June 2001

Various methods of segmental reconstruction have been described in an attempt to achieve limb salvage in tumour surgery. These include arthrodesis with autografts or allo-

F. Mittermayer, MD

M. Dominkus, MD

P. Krepler, MD

E. Schwameis, MD

M. Sluga, MD

R. Kotz, MD, Head of Department

Department of Orthopaedics

G. Strasser, MD

Department of Radiology

University of Vienna, Währinger Gürtel 18-20, A-1090 Vienna, Austria.

R. Windhager, MD

Department of Orthopaedics, University of Graz, Auenbruggerplatz 28, A8036 Graz, Austria.

Correspondence should be sent to Dr F. Mittermayer.

(C)2002 British Editorial Society of Bone and Joint Surgery 0301-620X/02/312204\$2.00 grafts, rotationplasty, bone transport techniques such as the Ilizarov method and arthroplasty using allografts. ${ }^{1-5}$ Endoprosthetic replacement in the lower limbs has become an established method, giving stability, early weight-bearing and good function. In the last 30 years, the overall five-year survival rate for tumour endoprostheses has increased from $20 \%$ to $85 \%$. Recent studies have suggested that aseptic loosening has replaced infection as the most frequent cause of failure. ${ }^{5-28}$ Therefore, the management of aseptic loosening has become the major concern in endoprosthetic reconstruction in limb-salvage surgery. Although the number of revision operations is increasing, information concerning the outcome after aseptic loosening is limited. ${ }^{25,27,29} \mathrm{We}$ present a retrospective study of the complication rates and the functional and radiological outcome after cementless revision operations for aseptic loosening.

\section{Patients and Methods}

We reviewed 251 patients who underwent surgery between September 1982 and September 1997. A cementless Kotz modular femoral and tibial reconstruction (KMFTR) or a Howmedica Modular Reconstruction System (HMRS; Howmedica GmBH, Kiel, Germany) endoprosthesis had been implanted after resection of a malignant tumour of the lower limb in all cases. There were 135 men and 116 women with a mean age of 37.6 years at the time of operation. Twenty-one (15 men, 6 women) (8.4\%) underwent a revision procedure for aseptic loosening at a mean of 36 months (11 to 121) after implantation (Table I). The indications for revision surgery included pain, instability and progressive changes on plain radiographs. The primary malignant tumour had been resected at a mean age of 23.0 years and the gap filled by an endoprosthesis. The primary pathology was osteosarcoma in 17, malignant fibrous histiocytoma in one, Ewing's sarcoma in one and chondrosarcoma in two. The locations were the proximal femur in two, the distal femur in 15 , and the proximal tibia in four. Nineteen patients had received neoadjuvant chemotherapy according to the COSS protocol ${ }^{22,26,30}$ and one according to the T11 protocol. ${ }^{22,30}$ In one patient (case 11) with a local recurrence of a G2 chondrosarcoma, no chemotherapy had been given. Radiotherapy was given to two. In two patients (cases 8 and 16), biopsy and initial chemotherapy and radiotherapy had been carried out in another country. 
Table I. Details of the 21 patients who underwent revision of the endoprosthesis in a lower limb

\begin{tabular}{|c|c|c|c|c|c|c|c|c|c|c|c|c|c|c|}
\hline \multirow[b]{2}{*}{ Case } & \multirow[b]{2}{*}{$\begin{array}{l}\text { Age } \\
(\mathbf{y r s})\end{array}$} & \multirow[b]{2}{*}{ Site* } & \multirow[b]{2}{*}{ Radiotherapy } & \multicolumn{3}{|c|}{ Resection length (cm) } & \multicolumn{3}{|c|}{ Type of prosthesis } & \multicolumn{4}{|c|}{ Complications after first revision } & \multirow[b]{2}{*}{$\begin{array}{l}\text { MSTS (\%) } \\
\text { score }\end{array}$} \\
\hline & & & & First op & $\begin{array}{l}\text { First } \\
\text { revision }\end{array}$ & $\begin{array}{l}\text { Second } \\
\text { revision }\end{array}$ & First op & $\begin{array}{l}\text { First } \\
\text { revision }\end{array}$ & $\begin{array}{l}\text { Second } \\
\text { revision }\end{array}$ & $\begin{array}{l}\text { Mths after } \\
\text { first op }\end{array}$ & First op & $\begin{array}{l}\text { Mths } \\
\text { after rev }\end{array}$ & Revision & \\
\hline 1 & 20 & PF & No & 19.0 & 0.0 & & KMFTR & HMRS & & 0 & Nerve palsy & & & 60 \\
\hline 2 & 23 & DF & No & 22.5 & 2.0 & & KMFTR & KMFTR & & 44 & Fracture & 72 & Bushing failure & 83 \\
\hline 3 & 17 & PT & No & 18.0 & 0.0 & & KMFTR & HMRS & & & & & & 100 \\
\hline 4 & 19 & $\mathrm{DF}$ & No & 13.5 & 4.0 & 0.0 & KMFTR & KMFTR & HMRS & 10 & Bushing failure & 72 & Aseptic loosening & 100 \\
\hline 5 & 18 & $\mathrm{DF}$ & No & 12.0 & 10.0 & & HMRS & HMRS & & & & & & 100 \\
\hline 6 & 15 & DF & No & 21.5 & 3.0 & & KMFTR & KMFTR & & & & & & 100 \\
\hline 7 & 42 & PT & No & 17.0 & 0.0 & 0.0 & KMFTR & HMRS & HMRS & 55 & Bushing failure & 63 & Aseptic loosening & 96 \\
\hline 8 & 18 & DF & Yes & 29.0 & 0.0 & 0.0 & KMFTR & KMFTR & HMRS & 52 & Aseptic loosening & & & 70 \\
\hline 9 & 19 & $\mathrm{DF}$ & No & 13.5 & 0.0 & & KMFTR & HMRS & & 0 & Haematoma & & & 100 \\
\hline 10 & 25 & PT & No & 17.0 & 4.0 & & KMFTR & HMRS & & 51 & Bushing failure & & & 90 \\
\hline 11 & 73 & $\mathrm{DF}$ & No & $11.0+3.0$ & 14.0 & & HMRS & HMRS & & & & & & 73 \\
\hline 12 & 19 & DF & No & 17.0 & 2.0 & & KMFTR & HMRS & & & & & & 100 \\
\hline 13 & 14 & DF & No & 16.5 & 6.0 & & KMFTR & HMRS & & & & & & 100 \\
\hline 14 & 18 & DF & No & - & 0.0 & 3.0 & KMFTR & KMFTR & KMFTR & 18 & Bushing failure & & & 100 \\
\hline 15 & 17 & $\mathrm{DF}$ & No & $19.0+3.0$ & 1.5 & 2.0 & KMFTR & KMFTR & HMRS & 55 & Aseptic loosening & & & 70 \\
\hline 16 & 30 & $\mathrm{PF}$ & Yes & 22.0 & 2.0 & & KMFTR & HMRS & & 40 & Aseptic loosening & & & 100 \\
\hline 17 & 16 & DF & No & 21.5 & 6.0 & & KMFTR & KMFTR & & 121 & Bushing failure & & & 100 \\
\hline 18 & 19 & DF & No & $9.5+2.0$ & 7.5 & & KMFTR & HMRS & & 50 & Bushing failure & & & 90 \\
\hline 19 & 16 & DF & No & 28.0 & 1.0 & & HMRS & HMRS & & & & & & 83 \\
\hline 20 & 16 & TR & No & $13.0+12.0$ & 1.0 & & KMFTR & HMRS & & & & & & 50 \\
\hline 21 & 29 & $\mathrm{DF}$ & No & 16.5 & 1.0 & & HMRS & HMRS & & & & & & 80 \\
\hline
\end{tabular}

* PF, proximal femur; DF, distal femur; PT, proximal tibia; TR, total replacement

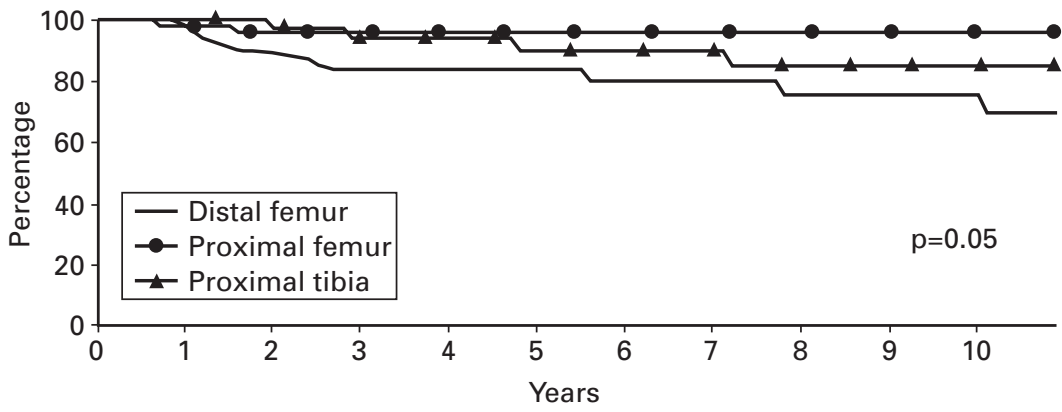

Fig. 1

Kaplan-Meier estimate of the survival rate without aseptic loosening of 251 patients according to the site of the prosthesis.

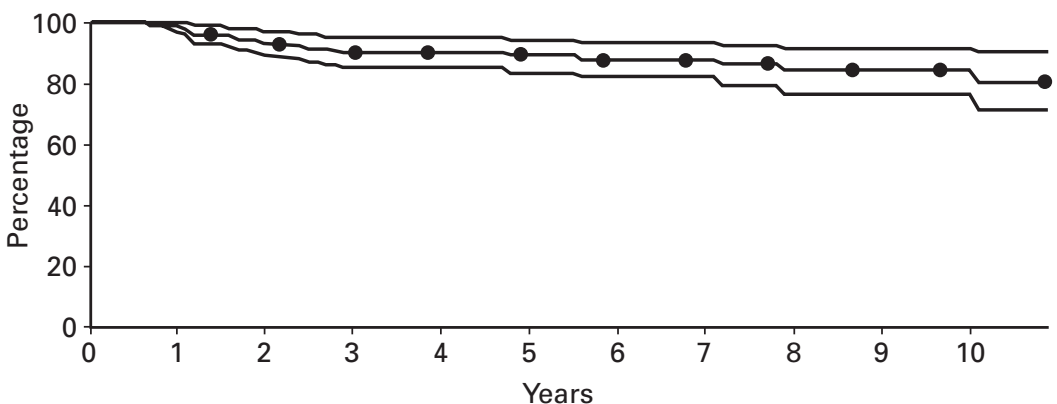

Fig. 2

Kaplan-Meier estimate of the overall survival rate without aseptic loosening of 251 patients.

The final clinical and radiological assessments of these 21 patients were undertaken at a mean follow-up of 101 months (47 to 155) after the initial operation. Laboratory tests, CT of the chest, abdominal sonography and ${ }^{99 \mathrm{~m}} \mathrm{Tc}$ bone scanning were performed as well as determination of the International Symposium of Limb Salvage (ISOLS) criteria $^{31}$ from a plain radiograph, and the functional Musculoskeletal Tumor Society (MSTS) score. ${ }^{32}$ The surgical technique and the details of the prosthesis have been described previously. ${ }^{8,16,17,20,33-35}$ All operations were carried out in a standardised manner.

At the revision procedure, the diaphyseal component was removed, the medullary canal was prepared again and a component with a longer stem and a larger diameter inserted, with adjustments to compensate for any resection of bone stock.

Statistical analysis. The overall time free from aseptic loosening was defined as the period between the date of the first implantation and the first revision operation. At the date of the last follow-up, or death of the patient, the respective overall time free from aseptic loosening was considered as 'censored' survival time. The probability of survival of the endoprosthesis was determined by the method of Kaplan and Meier. ${ }^{36}$ Differences between the 
groups were tested according to Mantel. ${ }^{37}$ The $95 \%$ confidence intervals for the Kaplan-Meier measurements were computed using Greenwood's formula. ${ }^{38}$ The SAS statistical analysis system (Version 8; SAS Institute Inc, Cary, North Carolina) was used for all calculations. All $\mathrm{p}$ values were the result of two-sided tests with a level of significance of $5 \%$.

\section{Results}

We found that the probability of a patient avoiding aseptic loosening for ten years was $96 \%$ for a proximal femoral, $76 \%$ for a distal femoral and $85 \%$ for a proximal tibial implant (Fig. 1). Figure 2 shows the Kaplan-Meier estimate of the overall time without aseptic loosening. There was a statistically significant difference in the risk of developing aseptic loosening at different sites with the highest incidence being in the distal femur, followed by the proximal tibia and the proximal femur $(p=0.05)$. The age of the patient, increasing in those under 30 years, was also a significant factor $(\mathrm{p}=0.001)$. Neither local radiotherapy $(p=0.82)$ nor gender $(p=0.07)$ had any effect.

After the primary procedure 12 patients had developed early complications including haematoma and wound necrosis or dehiscence. Ten had late complications including nerve palsy in three, periprosthetic fractures in four and joint contracture in one. One patient had required a synovectomy and one a reconstruction of the patellar ligament. Two patients had required a musculocutaneous free latissimus dorsi flap. In one patient (case 8) who had had preoperative radiotherapy, a free flap became necessary after four soft-tissue revision procedures had failed, and in another patient (case 20) because of skin necrosis after a wide resection of the knee.

The median time to the first revision operation for aseptic loosening was 27 months (13 to 121) after the initial operation. The initial procedure had been performed for a malignant tumour in the proximal femur in two patients, in the distal femur in 15 , in the proximal tibia in three and in both the distal femur and proximal tibia in one. In 18 patients the femoral component and in one the tibial component of the KMFTR prosthesis had to be changed. In two patients both the femoral and tibial anchorages were changed. In seven patients, the same type of implant was used in both the primary and revision procedures; the other 14 patients received a modified HMRS prosthesis at revision (Table I). ${ }^{16,20,35}$ In no case was bone cement used.

In six patients no further bone was resected at the time of revision. In 14 the mean resection length was $3.6 \mathrm{~cm}$ (Table I) and in one (case 11), in which a recurrence of tumour was suspected, a further wide resection including $14 \mathrm{~cm}$ of bone was undertaken. Most resections were necessary because of stress resorption of bone under the flanges of the prosthesis. In an attempt to reduce this, the number of flanges in the HMRS prostheses was reduced to one. This may explain the smaller amount of bone resected during the second revision operations. The diameter of the new stem was $1 \mathrm{~mm}$ greater than the original in nine patients, $2 \mathrm{~mm}$ in three, $3 \mathrm{~mm}$ in five and $4 \mathrm{~mm}$ in one. Apart from one haematoma, we encountered no soft-tissue complications after the revision operations.

In four patients, aseptic loosening of the prosthesis occurred at a mean of 21 months (9 to 41) after fracture of the stem of the implant. The incidence of complications was the same after the first operation as after the revisions (Table I). There was one case of nerve palsy (sciatic) and one fracture. Seven patients had late failure of the bushing. In three patients, a one-block bushing was implanted with additional metal rings and in four an HMRS bushing was used. $^{16,20,35}$

In five patients, a second revision procedure was carried out at a mean of 56.4 months (40 to 72) after the first. Aseptic loosening of a distal femoral component occurred three times, of the proximal femoral component once and of the proximal tibial component once. At the second revision procedure, one patient received a KMFTR and four an HMRS prosthesis. Of the five patients with repeat loosening, one (case 4), had undergone disarticulation through the contralateral knee three years before implantation of the KMFTR prosthesis for osteosarcoma. Although provided with an orthosis, he placed considerable stress on the endoprosthesis. In one patient (case 7), there was loosening of the non-modular femoral stem of a proximal tibial prosthesis. After preoperative radiotherapy and resection of $29 \mathrm{~cm}$ of femoral bone, one patient (case 8 ) required a vascularised free latissimus dorsi flap after four failed soft-tissue revision procedures. Both femoral and tibial components loosened synchronously in one patient (case 15). In another patient (case 16) the bone quality after radiotherapy was compromised causing a pathological fracture around the femoral stem. In only one patient (case 7) was cemented fixation used after a second revision for aseptic loosening had resulted in much bone loss. There were no other complications. The mean follow-up after the second revision operation was 30 months (2 to 50 ).

The first radiological signs of bone remodelling were seen at a mean of 12 months (4 to 23) after the first operation and of 23.3 months ( 2 to 117 ) before the revision operation (Fig. 3). The first clinical symptoms appeared at a mean of 4.6 months before the revision operation. A longer interval (mean 53.7 months) was found between the first radiological signs of loosening and the second revision operation. The mean duration between the onset of symptoms and the second revision operation was 12 months. At the first sign of aseptic loosening, we found either bone remodelling, sclerosis, resorption, hypertrophy of the cortex or radiolucent lines, around the most proximal or distal regions of the stem. At follow-up all radiographs were assessed to determine bone remodelling and the following were examined; the prosthesis-bone interface, bone anchorage and defects of the implant and its articulation according 


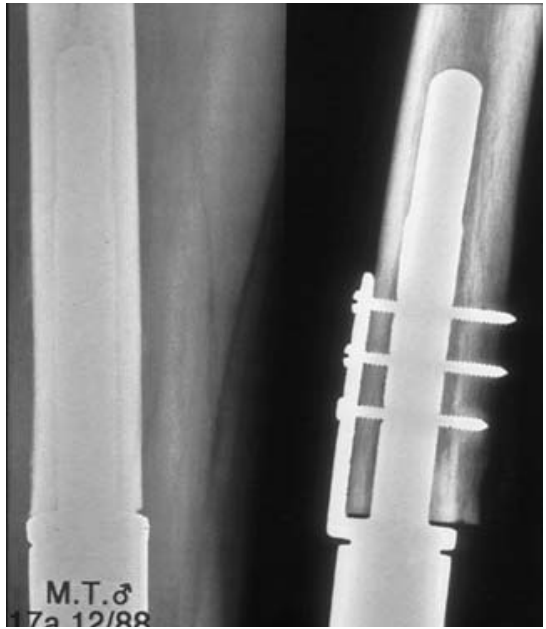

Fig. 3a

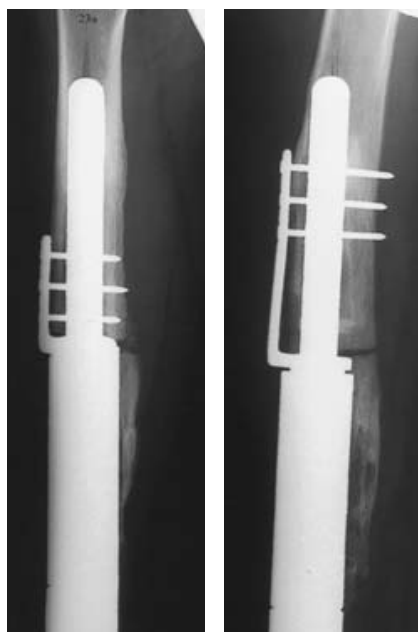

Fig. 3d

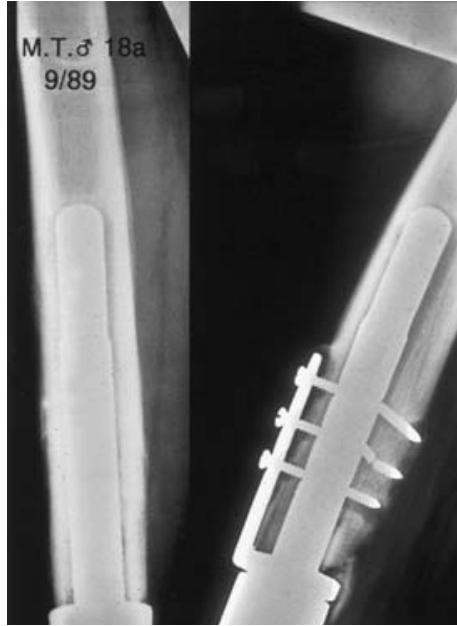

Fig. 3b

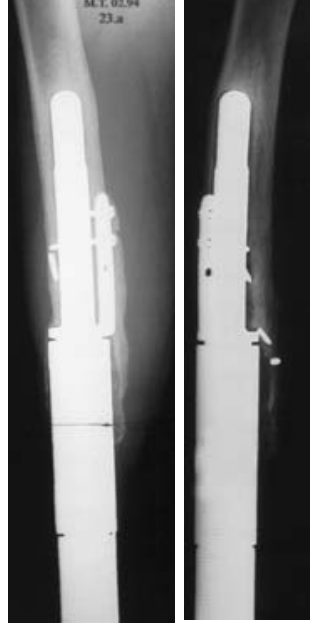

Fig. 3c

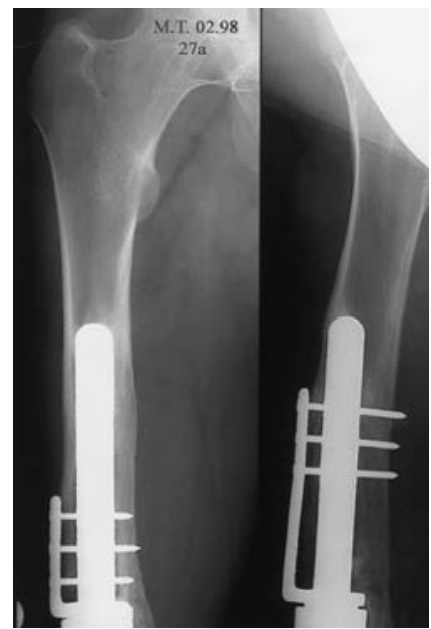

Fig. 3e

Case 15. Radiographs showing a KMFTR distal femoral replacement a) after implantation, b) and c) with aseptic loosening, d) after reoperation and e) at follow-up.

to the ISOLS criteria (Table II). Using the MSTS score, pain, function, emotional acceptance, the use of a walking stick and gait were assessed. The clinical results showed a mean functional performance of $88 \%$ of normal.

\section{Discussion}

Horowitz et $\mathrm{al}^{11}$ analysed the increasing incidence of aseptic loosening of cemented tumour prostheses in a long-term follow-up study. It was $19 \%$ after five years rising to $33 \%$ after ten. At five years they reported avoidance of aseptic loosening of $100 \%$ in the proximal femur, $78 \%$ in the distal femur and $73 \%$ in the proximal tibia. The significant increase in aseptic loosening in the long term could explain the better results with cementless tumour prostheses in several studies with a follow-up of only 24 to 51 months. $8,20,28$

Unwin et al, $^{23}$ reviewing 1001 patients with cemented
Table II. Radiological evaluation of the 21 patients according to the ISOLS criteria

\begin{tabular}{lcccc}
\hline & \multicolumn{4}{c}{ ISOLS (number of patients) } \\
\cline { 2 - 5 } & Excellent & Good & Fair & Poor \\
\hline Bone remodelling & 7 & 14 & 0 & 0 \\
Interface & 7 & 14 & 0 & 0 \\
Anchorage & 18 & 0 & 0 & 3 \\
Defects of the components of the implant & 21 & 0 & 0 & 0 \\
Defects of the articulation of the implant & 21 & 0 & 0 & 0 \\
\hline
\end{tabular}

custom-made prostheses, described the chances of avoiding aseptic loosening for ten years to be $93.8 \%$ for the proximal femoral, $67.4 \%$ for the distal femoral and $58 \%$ for the proximal tibial implant. They also reported a correlation between the incidence of aseptic loosening and the age of the patient, the amount of bone removed and time. Studies on rotating-hinge prostheses reported significantly better results, with rates of aseptic loosening of $0 \%$ to $10 \%$ at a 
follow-up of between 42 and 134 months. ${ }^{9,13}$ We have used the HMRS with a rotating hinge exclusively since 1996.

In our study of the cementless KMFTR prosthesis, with a flexion and extension hinge, we found the chance of avoiding aseptic loosening for ten years to be $96 \%$ for the proximal femoral, $76 \%$ for the distal femoral and $85 \%$ for the proximal tibial implant. Apart from the surgical site $(p=0.05)$ only the age of the patient at the initial operation ( $p=0.001$, rising for younger patients) showed a significant variation.

The mean age of the patients in our study, at the time of operation, was 23.0 years. Neither local radiotherapy $(\mathrm{p}=0.82)$ nor gender $(\mathrm{p}=0.07)$ had any influence on the development of aseptic loosening. We found an equal number of complications after the primary implantation as after the revision procedure for aseptic loosening. Ward and Eckardt $^{25}$ found a reduction in the MSTS functional rating by one grade after revision operations. Wirganowicz et $\mathrm{al}^{27}$ reported the functional results for patients after endoprosthetic revision to be either better, unchanged or only slightly worse than that in patients with a surviving endoprosthesis. After a mean follow-up of three years, Renard et $\mathrm{al}^{29}$ found a deterioration of functional results in five patients, an improvement in two and unchanged results in nine. No other authors have described their complication rates after revision procedures.

The functional outcome of an excellent result in $71.5 \%$, good in $19.0 \%$ and fair in $9.5 \%$ at the final follow-up in our series is comparable with that of other studies after midterm follow-up. Our functional results did not deteriorate after the revision operations. ${ }^{5-28} \mathrm{~A}$ further argument in favour of cementless revision surgery is the modest diaphyseal bone loss. All five patients with re-relapse of aseptic loosening were very difficult singular cases with extraordinary requirements. Reduction in stress resorption of the bone brought about by implantation of a HMRS prosthesis, careful preparation of the bone with as little damage to the periosteum as possible and an extended long stem-bone anchorage of the prosthesis result in a durable, stable fixation.

In these five patients the first radiological signs were found at a mean of ten months ( 7 to 13) before the revision operation. This, together with the special history and a shorter duration of clinical symptoms, could predict a more fulminant course of aseptic loosening in comparison with the 15 other patients. Before the second revision, radiological symptoms were observed for a mean of 54 months (39 to 90) which is significantly longer than before the first revision.

The first radiological signs of aseptic loosening were found at a mean of 12 months (4 to 23) after implantation and 23 months ( 2 to 117 ) before revision surgery. There were radiolucent lines or bone remodelling (sclerosis, resorption, hypertrophy) in all patients around the tip of the stem. Symptoms such as pain, instability and shortening, appeared at a mean of five months before the revision operation. As the onset of symptoms is gradual, most patients found it difficult to state precisely when they started. The question as to whether to respond quickly, at the first sign, either radiological or clinical, of aseptic loosening in order to save as much bone stock as possible, or to delay further surgery as long as possible because of the high incidence of complications, cannot be answered because of the small numbers in this series. Radiological evidence of loosening at the tip of the stem supports the hypothesis of the biomechanical micromovement at the most proximal and distal parts of the rigid implant, as being the cause for loosening, whereas loosening caused by polyethylene wear debris usually starts near the joint. ${ }^{30}$

Our study shows that a loose prosthesis can be replaced with another uncemented prosthesis, with no loss of function or adverse radiological features, and that there is no difference between the incidence of complications after the revision and the primary procedures.

The authors want to thank Teresa Zettl and Harald Heinzl, PhD, for assistance.

No benefits in any form have been received or will be received from a commercial party related directly or indirectly to the subject of this article.

\section{References}

1. Gebhardt MC, Flugstad DI, Springfield DS, Mankin HJ. The use of bone allografts for limb salvage in high-grade extremity osteosarcoma. Clin Orthop 1991;270:181-96.

2. Kotz R, Salzer M. Rotation-plasty for childhood osteosarcoma of the distal part of the femur. J Bone Joint Surg [Am] 1982;64-A:959-69.

3. Mankin HJ, Fogelson FS, Trasher AZ, Jaffer F. Massive resection and allograft replacement in the treatment of malignant bone tumors. N Engl J Med 1976;294:1247-55.

4. Mankin HJ, Doppelt SH, Sullivan TR, Tomford WW. Osteoarticular and intercalary allograft transplantation in the management of malignant tumors of bone. Cancer 1982;50:613-30.

5. Zehr RJ, Enneking WF, Scarborough MT. Allograft-prosthesis composite versus megaprosthesis in proximal femoral reconstruction. Clin Orthop 1996;322:207-23.

6. Abudu A, Carter SR, Grimer RJ. The outcome and functional results of diaphyseal endoprostheses after tumour excision. $J$ Bone Joint Surg [Br] 1996;78-B:652-7.

7. Cannon SR. Massive prostheses for malignant bone tumours of the limbs: Instructional Course Lecture. J Bone Joint Surg $[\mathrm{Br}]$ 1997;79-B:497-506.

8. Capanna R, Morris HG, Campanacci D, Del Ben M, Campanacci M. Modular uncemented prosthetic reconstruction after resection of tumours of the distal femur. J Bone Joint Surg [Br] 1994;76-B:17886.

9. Choong PFM, Sim FH, Pritchard DJ, Rock MG, Chao EYS. Megaprostheses after resection of distal femoral tumours: a rotating hinge design in 30 patients followed for 2-7 years. Acta Orthop Scand 1996;67:345-51.

10. Eckardt JJ, Matthews JG 2nd, Eilber FR. Endoprosthetic reconstruction after bone tumour resections of the proximal tibia. Orthop Clin North Am 1991;22:149-60.

11. Horowitz SM, Lane JM, Otis JC, Healey JH. Prosthetic arthroplasty of the knee after resection of a sarcoma in the proximal end of the tibia: a report of sixteen cases. J Bone Joint Surg [Am] 1991;73-A:286-93.

12. Horowitz SM, Glasser DB, Lane JM, Healey JH. Prosthetic and extremity survivorship after limb salvage for sarcoma: how long do the reconstructions last? Clin Orthop 1993;293:280-6.

13. Kabo JM, Yang RS, Dorey FJ, Eckardt JI. In vivo rotational stability of the kinematic rotating hinge knee prosthesis. Clin Orthop 1997;336:166-76. 
14. Kawai A, Muschler GF, Lane JM, Otis JC, Healey JH. Prosthetic knee replacement after resection of a malignant tumour of the distal part of the femur: medium to long-term results. J Bone Joint Surg [Am] 1998;80-A:636-47.

15. Kay MR, Kabo JM, Seeger LI, Eckardt JJ. Hydroxyapatite-coated distal femoral replacements: preliminary results. Clin Orthop 1994;302:92-100.

16. Kotz R. Tumourendoprothesen bei malignen Knochentumouren. Orthopäde 1993;22:160-6.

17. Kotz R, Ritschl P, Trachtenbrodt J. A modular femur tibia reconstruction system. Orthopaedics 1986;9:1639-52.

18. Malawer MM, Chou LB. Prosthetic survival and clinical results with use of large-segment replacements in the treatment of high-grade bone sarcomas. J Bone Joint Surg [Am] 1995;77-A:1154-65.

19. McKenna RJ, Schwinn CP, Soong KY, et al. Sarcomata of osteogenic series (osteosarcoma, fibrosarcoma, chondrosarcoma, parosteal osteogenic sarcoma, and sarcomata arising in abnormal bone): an analysis of 552 cases. J Bone Joint Surg [Am] 1966;48-A:1-26.

20. Ritschl P, Capanna R, Helwig U, Campanacci M, Kotz R. Modulares Tumorendoprothesensystem für die untere Extremität (Kotz-Modular-Femur-Tibia-Rekonstruktionssystem). Z Orthop 1992;130:290-3.

21. Roberts P, Chan D, Grimer RJ, Sneath RS, Scales JT. Prosthetic replacement of the distal femur for primary bone tumors. J Bone Joint Surg [Br] 1991;73-B:762-9.

22. Rosen G, Tan C, Sanmaneechal A, et al. The rationale for multiple drug chemotherapy in the treatment of osteogenic sarcoma. Cancer 1975;35:936-45.

23. Unwin PS, Cannon SR, Grimer RJ, et al. Aseptic loosening in cemented custom-made replacements for bone tumours of the lower limb. J Bone Joine Surg [Br] 1996;78-B:5-13.

24. Ward WG, Johnston KS, Dorey FJ, Eckardt JJ. Extramedullary porous coating to prevent diaphyseal osteolysis and radiolucent lines around proximal tibial replacements: a preliminary report. $J$ Bone Joint Surg [Am] 1993;75-A:976-87.

25. Ward WG, Eckardt JJ, Johnston-Jones KS, et al. Five to ten year results of custom endoprosthetic replacement of the distal femur. In: Brown KLB, ed. Complications of limb salvage. Montreal, International Society on Limb Salvage, 1991:483-91.
26. Winkler K, Beron G, Kotz R, et al. Neoadjuvant chemotherpay for osteogenic sarcoma: results of a cooperative German/Austrian study. $J$ Clin Oncol 1984;2:617-24.

27. Wirganowicz PZ, Eckardt JJ, Dorey FJ, Eilber FR, Kabo JM. Etiology and results of tumor endoprosthesis revision surgery in 64 patients. Clin Orthop 1999;358:64-74.

28. Zwart HJJ, Taminiau AHM, Schimmel JW, van Horn JR. Kotz modular femur and tibial replacement: 28 tumor cases followed for 3 (1-8) years. Acta Orthop Scand 1994;65:315-8.

29. Renard AJS, Veth RPH, Schreuder HWB, et al. Revisions of endoprosthetic reconstructions after limb salvage in musculosketal oncology. Arch Orthop Trauma Surg 1998;117:125-31.

30. Link MP, Goorin AM, Miser AW, et al. The effect of adjuvant chemotherapy on relapse-free survival in patients with osteosarcoma of the extremity. New Eng J Med 1986;134:1600-6.

31. Glasser D, Langlais F. The ISOLS Radiological Implants Evaluation System. In: Langlais F, Tomeno B, eds. Limb salvage: major reconstructions in oncologic and nontumoral conditions. Berlin, etc:Springer Verlag, 1991:23-31.

32. Enneking WF, Dunham W, Gebhardt MC, Malawer M, Pritchard DJ. A system for the functional evaluation of reconstructive procedures after surgical treatment of tumours of the musculoskeletal system. Clin Orthop 1993;286:241-61.

33. Capanna R, Leonessa C, Bettelli G, et al. Modular Kotz prosthesis: the Rizzoli Experience. In: Yamamuro T, ed. New developments for limb salvage in musculoskeletal tumours. Tokyo, etc: Springer-Verlag, 1989:37-44.

34. Kotz R, Pongracz N, Fellinger EJ, Ritschl P. Uncemented hinge prostheses with reinsertion of the ligamentum patellae. In: Yamamuro T, ed. New developments for limb salvage in musculoskeletal tumours. New York: Springer Verlag, 1989:605-10.

35. Kotz R, Ritschl P, Kropej D, Capanna R. Cementless modular prostheses: basic concepts and evolution. Chir Organi Mov 1990;75(1 Suppl):177-8.

36. Kaplan EL, Meier P. Nonparametric estimation from incomplete observations. J Am Stat Assoc 1958;53:457-81.

37. Mantel N. Evaluation of survival data and two new rank order statistics arising in its consideration. Cancer Chemother Rep 1966;50:163-70.

38. Kalbfleisch JD, Ross L. Prentice: the statistical analysis of failure time data. John Wiley and Sons, 1980. 